\title{
NUTRIENT RECOVERY FROM SOURCE SEPARATED URINE USING LIME
}

\author{
Zeeshan Ahmed Shakir \\ School of Engineering \\ Western Sydney University, New South Wales, Australia
}

\begin{abstract}
The approach of utilising source-separation method for separating human urine is being favoured as a very efficient alternative to the conventional methods of human waste disposal as it results in contraction of nutrient loads in wastewater treatment plants. (Yao et. al., 2017) In the course of our research work, we will opt for the preparation of a synthetic urine sample to be subject to our tests and procedure. This decision is informed on the basis of the fact that collection of real urine samples might be subject to contamination /activities that would eventually affect the results of the tests to be carried out. Some of these concerns can range from, health condition of the sample donor, exposure conditions during storage and transportation. etc. The general basic composition of the synthetic sample would include, $\mathrm{HCl}$ solution, ammonia $\left(\mathrm{NH}_{3}\right)$ solution, $\mathrm{NaCl}$ (sodium chloride), potassium chloride $(\mathrm{KCl})$, calcium chloride $(\mathrm{CaCl})$, magnesium sulphate $\left(\mathrm{MgSO}_{4}\right)$ and any available known phosphate solution such as magnesium phosphate. $\mathrm{Ca}(\mathrm{OH})_{2}$ would be our preferred lime solution both for the stabilization of the urine sample (thus preventing an occurrence of the enzymatic hydrolysis) and subsequent extraction of the phosphate nutrient. The quantity of lime solution required is dependent of the composition and mix of the urine sample. Research shows that $\mathrm{Ca}(\mathrm{OH})_{2}$ powder weighing between 4.3 - 5.8 grams dissolved in one litre of synthetic urine solution and kept at a constant temperature between 20 to 25 degrees Celsius, would stabilize the solution to a pH value of about 12.5 which is greater than a $\mathrm{pH}$ of 11 that would catalyse the enzymatic urea hydrolysis. (Randall et. al., 2016). Temperature conditions below 14 degrees Celsius would likely increase the saturation $\mathrm{pH}$ to values higher than 13 thereby increasing the chances of a hydrolysis occurrence.
\end{abstract}

\section{Keywords-Source Separation, Nutrient Recovery}

\section{INTRODUCTION}

The sustainable concepts of potent wastewater treatment options consist of removal of pollutants and recovery of important components. The nutrients nitrogen and phosphorus are primary supplements for plants yet when they present in different effluents formed by human activities cause eutrophication of surface water (Mitrogiannis, et al., 2018).
Urine is a mixture of various substances. The compounds present in the urine individually or inclusively can impose serious negative effects to the human and environment. Though, if the right compound is practiced at the proper location at an ideal quantity, it can carry potential for valuable reuse. The urine treatment processes increase the beneficial reuse of substances at the same time decrease the potential negative impacts (team, 2016). The human urine contains highest percentage of phosphorus of $55-75 \%$ and nitrogen 80 $90 \%$ to the waste stream (Tilley, 2006). Source separation and treatment of urine have gained lot of interest and are identified as resource-efficient substitutes to traditional urban drainage. Due to the high concentrations of phosphorus and nitrogen in urine than domestic wastewater, removal and effective recovery of these nutrients can be achieved cost effectively (Yao, et al., 2017). Moreover, urine can be converted from waste water stream to sustainable source of important nutrients by recovering nutrients for crop fertilization. Phosphorus is a valuable nutrient for plants, but it has been becoming non-renewable element because depletion of phosphate rocks, if phosphate can recover from urine it could meet $22 \%$ of the global demand (Mitrogiannis, et al., 2018).

\section{METHODOLOGY}

\section{A. Preparation of Synthetic Urine -}

According to Udert et al. (2006) synthetic urine will consist of different chemical compounds such as ammonium chloride, calcium chloride, sodium sulphate, magnesium chloride, dipotassium phosphate, potassium chloride and sodium chloride. The following table shows the composition of each chemical.

\begin{tabular}{|l|l|}
\hline Component & Quantity \\
\hline Water & 1 Litre \\
\hline Urea & $16 \mathrm{~g}$ \\
\hline $\mathrm{NH}_{4} \mathrm{Cl}$ & $1.80 \mathrm{~g}$ \\
\hline $\mathrm{Na}_{2} \mathrm{SO}_{4}$ & $2.30 \mathrm{~g}$ \\
\hline $\mathrm{NaH}_{2} \mathrm{PO}_{4}$ & $2.90 \mathrm{~g}$ \\
\hline $\mathrm{KCl}$ & $4.20 \mathrm{~g}$ \\
\hline $\mathrm{MgCl}_{2}$ & $0.370 \mathrm{~g}$ \\
\hline $\mathrm{CaCl}_{2}$ & $0.510 \mathrm{~g}$ \\
\hline $\mathrm{NaCl}$ & $0.183 \mathrm{~g}$ \\
\hline $\mathrm{NaOH}$ & 0.230 \\
\hline
\end{tabular}




\section{International Journal of Engineering Applied Sciences and Technology, 2020 \\ Vol. 5, Issue 6, ISSN No. 2455-2143, Pages 49-52 \\ Published Online October 2020 in IJEAST (http://www.ijeast.com)}

Table 1. Composition of Synthetic Urine according to Udert et al

After preparing the solutions for each component, in a beaker $100 \mathrm{ml}$ quantity of sample taken from each solution the total constitutes $700 \mathrm{ml}$ to this 4.2 grams of urea is added (urea composition is $6 \mathrm{~g} / \mathrm{l}$ but for $700 \mathrm{ml}$ its value is $4.2 \mathrm{gm}$ ). The final solution is divided into two equal parts of 350 and taken into two different beakers. To conduct $\mathrm{pH}$ experiments calcium hydroxide $40 \mathrm{~g} / \mathrm{l}$ solution is prepared by adding $40 \mathrm{gm}$ of calcium hydroxide to $1000 \mathrm{ml}$ of water. To measure $\mathrm{pH}$ values of the solutions the $\mathrm{pH}$ meter is standardized by using buffer solutions of 4,7 and $10 \mathrm{pH}$ values. Then the initial values of $\mathrm{pH}$ of solutions in the beakers are measured and around $5 \mathrm{ml}$ of sample solution taken in the small tubes before adding lime to the solutions. After that using a $10-1000 \mu l$ range pipette calcium hydroxide is added to the solution in the first beaker in batches and every time the $\mathrm{pH}$ values are recorded, the lime solution added to the urine until reaching $8 \mathrm{pH}$ values in one beaker and $\mathrm{pH} 9$ for second beaker. The same experiment is carried out for achieving $\mathrm{pH}$ values of 10,11 and 12 and the recorded values of calcium hydroxide are tabulated.

The five final solutions after adding lime of $\mathrm{pH}$ values $8,9,10$, 11 , and 12 are placed under the flocculator and speed $20 \mathrm{rpm}$ is adjusted also initial time is noted, during agitation for different time intervals of $5 \mathrm{~m}, 15 \mathrm{~m}, 30 \mathrm{~m}, 1 \mathrm{hr}$ and $2 \mathrm{hrs}, 15 \mathrm{ml}$ of samples are taken from each beaker and are stored in small tubes after filtrating the solution with filtrate and are labelled clearly.

The above experiments are done by considering ammonium chloride in synthetic urine preparation and without adding ammonium chloride while synthetic urine preparation. The recorded values of lime quantities for different $\mathrm{pH}$ values for the solutions with ammonia and without ammonia are shown in the table:

\begin{tabular}{|l|l|l|l|l|l|l|l|l|l|l|}
\hline $\begin{array}{l}\text { Type of } \\
\text { solution }\end{array}$ & \multicolumn{9}{|l|}{ Solution with ammonia } & \multicolumn{6}{|l|}{$\begin{array}{l}\text { Solution without } \\
\text { ammonia }\end{array}$} \\
\hline $\begin{array}{l}\mathrm{Ph} \\
\text { values }\end{array}$ & 8 & 9 & 10 & 11 & 12 & 8 & 9 & 10 & 11 & 12 \\
\hline $\begin{array}{l}\mathrm{Ca}(\mathrm{OH}) 2 \\
\text { added }\end{array}$ & 12 & 17.5 & 21.5 & 24.5 & 28 & 14 & 16 & 18.2 & 21.2 & \\
\hline
\end{tabular}

Table 2. Amount of $\mathrm{Ca}(\mathrm{OH})_{2}$ required to achieve different $\mathrm{pH}$ values

\section{B. Galery Experiments -}

To determine the amount of phosphorus and ammonia that can be extracted from the urine the solutions from the flocculator experiments are in the gallery equipment analyzed by using ammonia and phosphorus reagents. The dilution experiments are carried out in a manner that in cuvette- $01800 \mu \mathrm{l}$ of distilled water is taken with the help of micro pipette and other cuvette- 1 also filled with $1800 \mu \mathrm{l}$ of distilled water and it fixed in the cuvette rock then from the ph- 8 solution with 5 minutes agitation time $200 \mu \mathrm{l}$ of sample taken by pipette and added to the cuvette- 0 by gently stirring in order to mix the two samples, from this cuvette $200 \mu \mathrm{l}$ of sample is extracted to added to the cuvette-1. This process is repeated for other $\mathrm{pH}$ values: $8,9,10,11$, and 12 of time intervals: $5 \mathrm{~m}, 15 \mathrm{~m}, 30 \mathrm{~m}$, $1 \mathrm{hr}$ and $2 \mathrm{hr}$. The cuvette rack has 9 carriages in each carriage the samples from the dilution experiments placed for each $\mathrm{pH}$ value of different intervals and names are given to each carriage to identify the samples. While dilution experiments, the concentrated sample is diluted by 20 times to the initial value, so the dilution factor is 20 .

The cuvette racks are placed inside the gallery equipment with ammonia and phosphorus reagents then names for the samples with respect to carriage is given to the software and target compounds ammonia A and phosphorus Sai are selected to measure their concentration in the samples. It is taken 30 minutes to analyze the samples after finishing the process the values are printed from the software.

\section{RESUlt AND DisCUSSION}

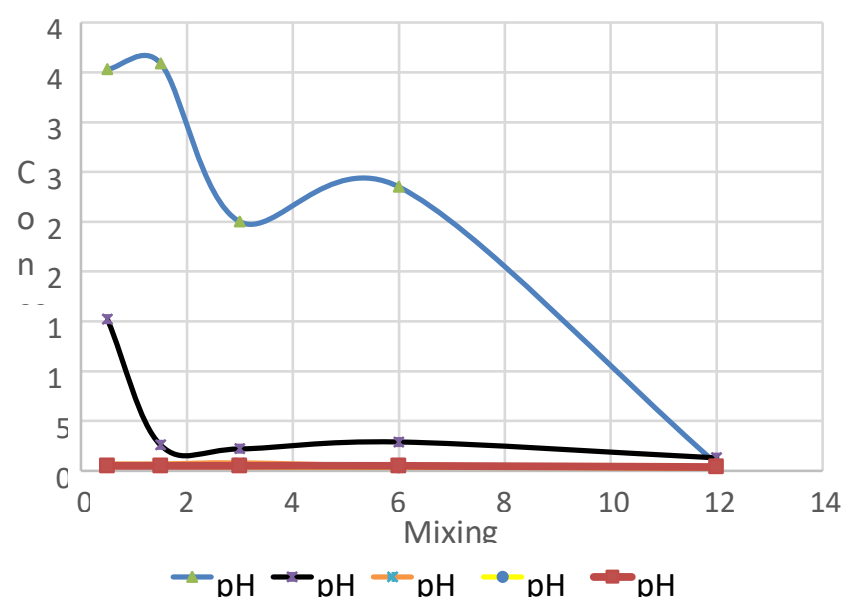

Fig 1. Comparative Study of all the $\mathrm{pH}$ for study of Phosphorus (without Ammonia)

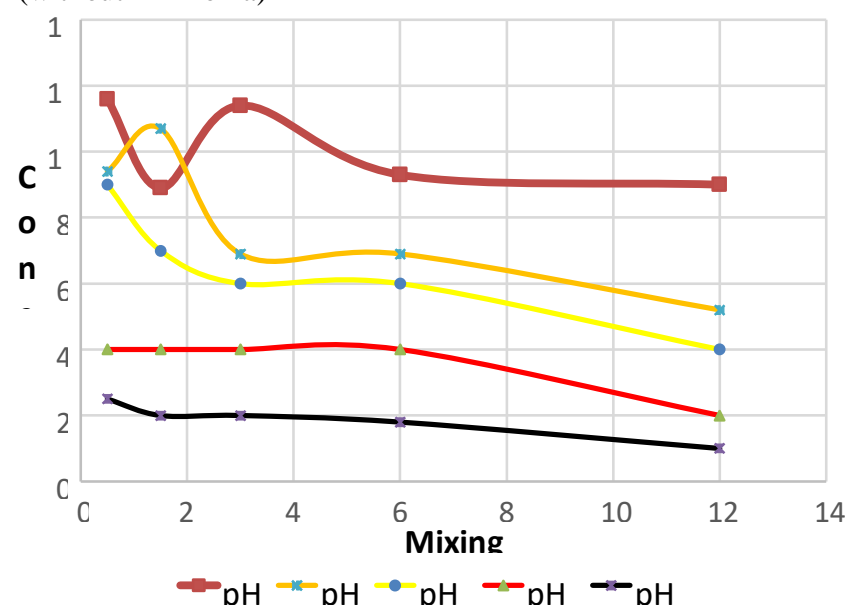




\section{International Journal of Engineering Applied Sciences and Technology, 2020 \\ Vol. 5, Issue 6, ISSN No. 2455-2143, Pages 49-52 \\ Published Online October 2020 in IJEAST (http://www.ijeast.com)}

Fig. 2. Comparative Study of all the $\mathrm{pH}$ for study of Phosphorus (with added Ammonia in Urine)

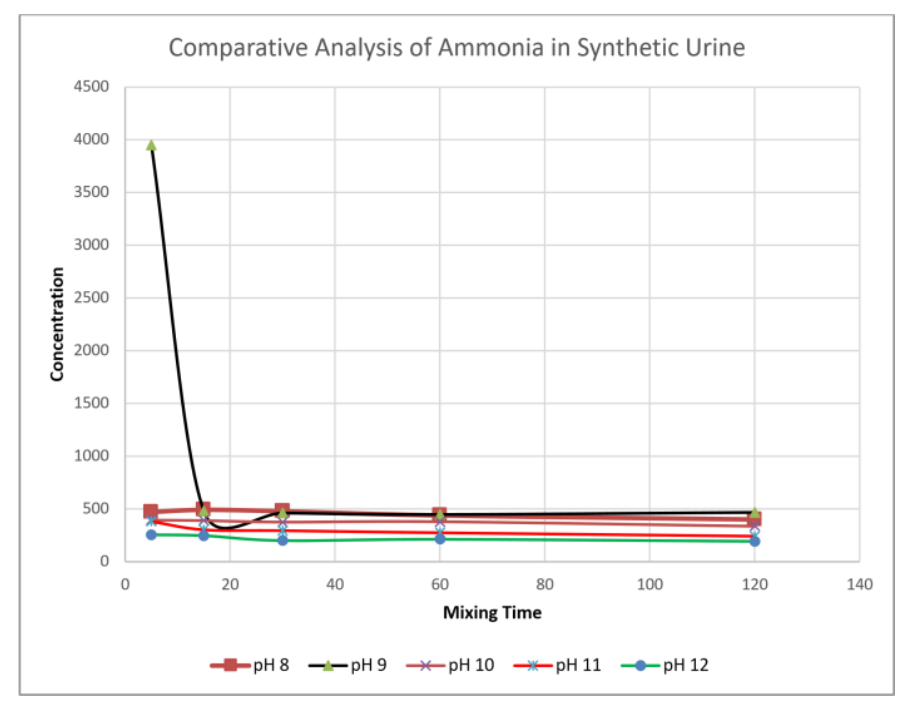

Fig. 3. Comparative Study of all the $\mathrm{pH}$ for study of Ammonia (without Ammonia added in Synthetic Urine)

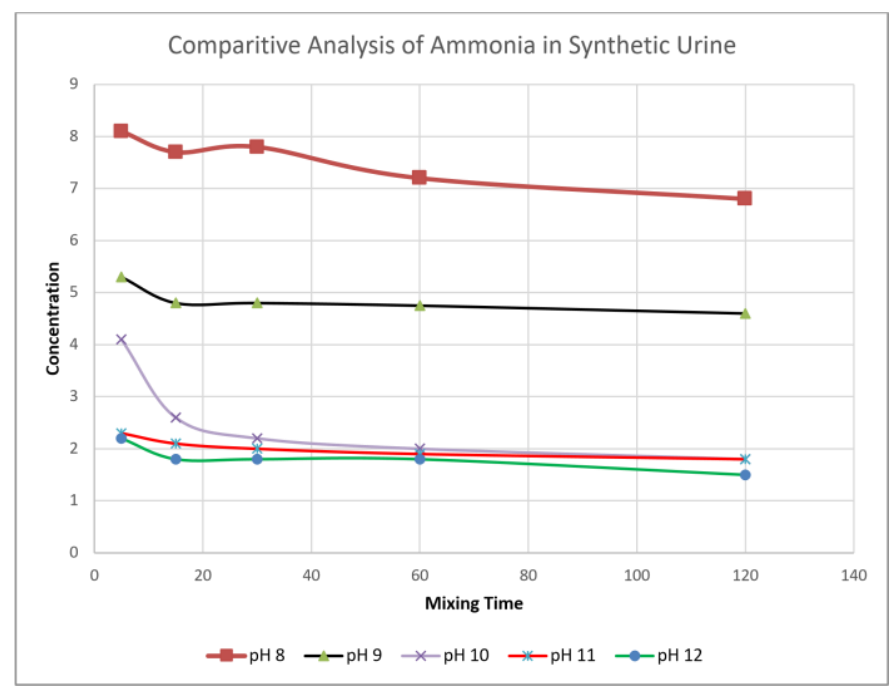

Fig. 4. Comparative Study of all the $\mathrm{pH}$ for study of Ammonia (with Ammonia added in Synthetic

Urine)

From the scenarios considered in our experiment that include the nutrient recovery of both Ammonia and Phosphorus from synthetic urine with and without added Ammonia, it can be said that the lower the $\mathrm{pH}$ the higher concentration of nutrients can be recovered. However, to recover all the nutrients (or most of the nutrients), it is seen that the higher $\mathrm{pH}$ values seems to recover most of the nutrients in all the considered cases in our experiment.

Hence it can be said that lower $\mathrm{pH}$ value recovers higher concentration of nutrients.

Another important thing that can be noticed in all the above considered scenarios is that the highest recovery of nutrient concentration is done during the initial mixing stages. However, further mixing stages help to recover most of the nutrients present in the urine. Calcium Hydroxide plays a role of stabilizing the Urine as well as increasing the $\mathrm{pH}$ of the urine up to $\mathrm{pH} 12$ in order to recover most of the available nutrients.

\section{CONCLUSION}

The essence of macronutrients such as Nitrogen and Phosphorous remain vital for life on earth. Source separation and removal from urine and waste-water sources is beneficial, not only for the reuse of these nutrients in agricultural applications, but as well critical to mitigate environmental hazards. This practice is in line with the global sustainability concepts whereby wastewater can be exploited for energy renewal. While diverse technologies exist in achieving this goal, biological nitrification and chemical precipitation are the most popular in recovering nitrogen and phosphorous respectively.

For this project, Calcium Hydroxide $\mathrm{Ca}(\mathrm{OH})_{2}$ played a dual role of stabilising the synthetic urine samples by increasing the $\mathrm{pH}$ values under controlled temperature and isolation / precipitation of the result nutrients. The resultant ammonium was converted to ammonia gas and phosphorous precipitated as a Calcium Phosphate (Ca-P) compound. The experiment was carried out using $700 \mathrm{~mL}$ of synthetic laboratory prepared

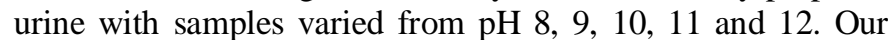
results show that $80-90 \%$ of Nitrogen and $95 \%$ of Phosphorous (after oven baking to precipitate salt) can be harvested.

\section{REFERENCE}

[1] Acién, F.G., Fernández, J.M., Magán, J.J. and Molina, E. (2012). Production cost of a real microalgae production plant and strategies to reduce it. Biotechnology advances, 30(6), pp.1344-1353.

[2] Coppens, A., Marijn Speeckaert, and Joris Delanghe. (2010)."The pre-analytical challenges of routine urinalysis." Acta Clinica Belgica 65, no. 3 : 182-189.

[3] Luo, Y., Guo, W., Ngo, H.H., Nghiem, L.D., Hai, F.I., Zhang, J., Liang, S. and Wang, X.C. (2014). A review on the occurrence of micropollutants in the aquatic environment and their fate and removal during wastewater treatment. Science of the total environment, 473, pp.619-641. 
[4] Wilsenach, J. \& Loosdrecht, M. V. (2003). Impact of separate urine collection on wastewater treatment systems. Water Science Technology, 48(1), pp. 103-110

[5] Udert, K. \& Wachter, M. (2012). Complete nutrient recovery from sourceseparated urine by nitrification and distillation. Water Research, 46(2), pp. 453-464.

[6] Maurer, M., Pronk, W. \& Larson, T. (2006). Treatment processes for source separated urine. Water Research, 40(17), pp. 3151-3166.

[7] K.M, U. et al. (2003). Nitrification and autotrophic denitrification of, Dübendorf, Switzerland: Swiss Federal Institute for Aquatic Science and Technology (EAWAG).

[8] Hu, M. et al. (2016). Constructing the ecological sanitation: a review on technology and methods. Journal of Cleaner Production, Volume 15, pp. 1-21.

[9] Zhang, j. et al. (2014). Mining Nutrients (N,P,K) Source seperated urine by Forward osmosis Dewatering. Environmental Science and Technology, Volume 48, pp. 3386-3394.

[10] Udert, K., Larson, T. \& Gujer, W. (2006). Fate of major compounds in source seperated urine. Water science and technoogy, 54(11), pp. 413-420.

[11] Volpin, F. et al. (2018). Simultaneous phosphorous and nitrogen recovery from source-separated urine: A novel application for fertilizer drawn forward osmosis. Chemosphere, Volume 203, pp. 482- 489.

[12] M., Shon, H. K., R.Grey, S. \& M. E. (2016). Membranebased processes for wastewater nutrient recovery: Technology, challenges, and future direction. Water Research, 89(1), pp. 210-221.

[13] Ledesma, P. et al. (2015). Source-separated urine opens golden opportunities for microbial electrochemical technologies. Trends in Biotechnology, 33(4), pp. 214220.

[14] Ikematsu, M., Kaneda, K., Iseki, M. \& Yasuda, M. (2007). Electrochemical treatment of human urine for its storage and reuse as flush water. Science of the total environment, 382(1), pp. 159-164.

[15] G. Randall, D. et al. (2016). A novel approach for stabilizing fresh urine by calcium hydroxide addition. Water Research, Volume 95, pp. 361-369.

[16] D Doyle, J. \& A Parsons, S. (2002). Struvite formation, control and recovery. Water Research, 36(16), pp. 39253940 . 